\title{
BUDAYA TABOT BENGKULU SEBAGAI PENDEKATAN PEMBELAJARAN BANGUN RUANG BERBASIS ETNOMATEMATIKA
}

\author{
Mahyudi $^{1}$, Rofika Sah Yanti ${ }^{2}$ \\ Universitas Muhammadiyah Bengkulu ${ }^{1,2}$ \\ didimahyudi21@gmail.com ${ }^{1}$
}

\begin{abstract}
ABSTRAK
Proses pembelajaran matematika di sekolah masih bersifat monoton dengan guru sebagai pusat pembelajaran dan metode belajar yang konvensional. Padahal matematika yang sifatnya abstrak, sangat menuntut guru untuk melakukan inovasi pembelajaran di kelas supaya siswa tidak merasa jenuh dan bosan. Hal inilah yang mengakibatkan siswa malas untuk mempelajari matematika. Untuk itu, guru harus membuat pembelajaran yang melibatkan siswa secara aktif dan bersifat kontekstual dengan kehidupan sehari-hari. Pembelajaran matematika realistik dengan pendekatan etnomatematika menjadi satu alternatif untuk mengatasi hal ini. Pendekatan pembelajaran dengan etnomatematika dapat menjembatani matematika dalam kehidupan sehari-hari yang berbasis budaya lokal. Penelitian ini merupakan deskriptif kualitatif dengan pendekatan etnografi untuk menggambarkan pemanfaatan budaya lokal tabot sebagai media pembelajaran bangun ruang berbasis etnomatematika. Informasi diperoleh melalui dokumentasi, observasi dan wawancara. Banyak hal yang dapat dimanfaatkan dari budaya lokal seperti budaya Tabot Bengkulu yang berhubungan dengan pembelajaran bangun ruang di sekolah. Bagian-bagian dari tabot terbentuk dari beberapa bangun ruang seperti, kubus, balok, limas terpancung. Bentuk-bentuk inilah yang kemudian dapat dimanfaatkan sebagai media pembelajaran matematika pada materi bangun ruang.
\end{abstract}

Kata kunci : bangun ruang, etnomatematika, kontekstual, realistik

\begin{abstract}
The process of learning mathematics in schools is still monotonous with the teacher as the center of learning and conventional learning methods. Even though mathematics which is abstract in nature, really requires teachers to innovate learning in the classroom so that students do not feel bored and bored. This has made students lazy to learn mathematics. For this reason, teachers must make learning that involves students actively and is contextual in their daily lives. Learning realistic mathematics with ethnomatematics approach becomes an alternative to overcome this. Learning approach with ethnomatematics can bridge mathematics in daily life based on local culture. This research is a qualitative descriptive ethnographic approach to illustrate the use of local culture as a medium of learning media based on ethnomatics. Information obtained through documentation, observation and interviews. Many things can be utilized from local culture such as Bengkulu Tabot culture that is related to learning to build space in schools. Parts of the tabot are formed from several building blocks such as cubes, beams, pyramid and beheaded. These forms can
\end{abstract}


then be used as a medium for learning mathematics in the material of building space.

Keywords : building space, ethnomatematics, contextual, realistic

\section{PENDAHULUAN}

Matematika sebagai salah satu ilmu dasar sudah diperkenalkan sejak anakanak masih duduk di Taman kanak-kanak. Hal ini menjadi penting karena matematika merupakan salah satu ilmu untuk memahami fenomena dalam kehidupan sehari-hari. Namun dalam pelaksanaannya, proses pembelajaran matematika mulai dari SD bahkan sampai perguruan tinggi masih bersifat teoritis dan kurang kontekstual. Pembelajaran cenderung menekankan pada rumus-rumus dan pemecahan masalah. Hal ini berakibat pada rendahnya minat dan motivasi siswa pada pelajaran matematika.

Pembelajaran matematika sebenarnya telah menyatu dengan kehidupan seharihari siswa itu sendiri. Matematika memegang peran penting karena merupakan ilmu pengetahuan yang mempunyai aplikasi sangat luas pada aspek kehidupan, dan bahkan banyak masalah yang dapat diselesaikan dengan matematika. Pembelajaran matematika yang realistik dapat dilakukan dengan menghubungkan pembelajaran matematika dengan kebudayaan yang ada di masyarakat sekitar (Sugiman, 2008). Pembelajaran matematika dapat dihubungkan dengan budaya lokal menggunakan pembelajaran berbasis etnomatematika. Bishop (2001) mengatakan bahwa perspektif sosial budaya merupakan hal penting dalam memahami peran nilai-nilai dalam pendidikan matematika.

Etnomatematika adalah suatu ranah kajian yang meneliti cara sekelompok orang pada budaya tertentu dalam memahami, mengekspresikan, dan menggunakan konsep-konsep serta praktik-praktik kebudayaan yang digambarkan sebagai sesuatu yang matematis (Wahyuni, 2013). Dalam menerapkan Etnomatematika diperlukan suatu model pembelajaran matematika yang realistik. Hal ini untuk memudahkan implementasinya dalam proses belajar mengajar, sehingga siswa dapat dengan mudah menyerap materi yang disampaikan. Matematika yang sifatnya abstrak akan lebih mudah dipahami siswa, dengan mengaplikasikannya dalam kehidupan sehari-hari.

Kajian tentang kaitan etnomatematika dalam pembelajaran matematika telah banyak dilakukan baik di Indonesia maupun di negara lain. Penelitian Tandiling (2013) terhadap suku dayak Kanayat'n mendapatkan gambaran rinci kegiatan dalam kehidupan sehari-hari pada masyarakat Dayak Kanayat'n yang bernuansa matematika. Kegiatan tersebut dapat dikelompokkan dalam membilang, mengukur, menentukan lokasi, merancang bangun, bermain dan menjelaskan. Sirate (2012) mengkaji implementasi etnomatematika dalam pembelajaran matematika. Hasil penelitian yang diperoleh menunjukkan bahwa dalam proses pembelajaran matematika, guru telah memanfaatkan etnomatematika dalam pembelajaran matematika sebagai sarana untuk memotivasi, menstimulasi siswa dalam mengatasi kejenuhan dan memberikan nuansa baru pada pembelajaran matematika.

Begitu pun Marsigit, dkk. (2018) mengungkapkan bahwa pembelajaran matematika berbasis etnomatematika selaras dengan matematika sekolah sebagai alat komunikasi dan kegiatan pemecahan masalah. Sementara dari hasil penelitian Widada, Herawaty dan Lubis (2018) diperoleh hasil bahwa kemampuan pemahaman 
konsep matematika siswa yang mendapat materi berbasis etnomatematika Bengkulu lebih baik daripada siswa yang mendapat materi tidak berbasis etnomatematika. Berdasarkan pembahasan tersebut, jelaslah bahwa etnomatematika memiliki pengaruh dalam pembelajaran matematika sekolah formal, etnomatematika memberikan makna kontekstual yang diperlukan untuk banyak konsep matematika yang abstrak.

Hasil-hasil penelitian ini memberikan arahan bahwa pembelajaran matematika berbasis etnomatematika dapat menjadikan pembelajaran menjadi lebih menarik yang berimbas pada meningkatnya kemampuan siswa dalam memahami materimateri matematika. Selain itu, pembelajaran ini dapat menjadi alternatif untuk membuat pembelajaran lebih bervariasi sehingga tidak monoton dan membosankan siswa.

\section{METODE}

Penelitian ini merupakan deskriptif kualitatif dengan pendekatan etnografi untuk menggambarkan pemanfaatan budaya lokal tabot sebagai media pembelajaran bangun ruang berbasis etnomatematika. Informasi diperoleh melalui dokumentasi, observasi dan wawancara.

\section{HASIL DAN PEMBAHASAN}

\section{1) Sejarah budaya Tabot}

Dikutip dari Direktorat Sejarah dan Nilai Tradisional Depdikbud (1992) tentang sejarah singkat acara Tabot di Kota Bengkulu. Tabot telah diselenggarakan secara turun-temurun sejak abad ke 14, sejarah perayaan Tabot di Bengkulu pertama kali dirayakan oleh Syeh Burhanuddin yang lebih populer sebagai Imam Senggolo tahun 1685. Pernikahan Imam Senggolo, dengan wanita Bengkulu kemudian anak, cucu, dan keturunannya disebut sebagai keluarga Tabot. Latar belakang Festival Tabot, ini yaitu untuk mengingat atas kematian cucu Nabi Muhammad yaitu Husein bin Ali bin Abi Thalib, yang wafat di padang Karbala (Irak).

Selain telah menjadi Tradisi sejak lama, Tabot akhirnya dipandang sebagai upacara Tradisional di Kota Bengkulu. Asal Usul Nama Tabot. Tabot berasal dari kata At-Tabut, yang secara Harfiah memiliki arti kotak atau peti, At-Tabut sudah ada sejak zaman Nabi Musa dan Harun, pada waktu itu At- Tabut dibawa turun ke bumi oleh malaikat. Menurut kepercayaan Bani Israel, At-Tabut ini adalah sebuah peti atau kotak tempat menyimpan jenazah pemimpin mereka. Mereka meyakini bahwa AtTabut harus tetap berada di tangan mereka karena hal ini akan mendatangkan kebaikan. Sebaliknya musibah akan datang apabila At-Tabut tidak berada di tangan mereka, At- Tabut dalam bentuk yang lain muncul pada waktu terjadinya perang antara Amir Hussain (сиси Nabi Muhammad SAW) melawan kaum Khawarij di Padang Karbala (Irak). Dalam pertempuran di Karbala Amir Hussain dan pengikutnya mengalami kekalahan karena jumlah yang tidak seimbang, Amir Hussain sendiri gugur dengan tangan dan kepala yang terpisah dari badan. Ketika tubuh Amir Hussain yang sudah tidak berkepala dan bertangan itu diketemukan kembali oleh para pengikutnya, maka turunlah bangunan aneh yang sangat Indah dan mengangkat tubuh Amir Hussain.

Bangunan Indah, yang membawa Jenazah Hussain itu kemudian disebut Tabut (Tabot dalam dialek bahasa Bengkulu), sejak saat itu perayaan Tabut dilaksanakan 
setiap tahun selama 10 hari dalam bulan Muharram oleh para pengikut Imam Hussain. Upacara Ritual Tabot sampai di Bengkulu dibawa oleh para penyebar agama Islam dari Punjab, para penyebar agama Islam dari Punjab yang datang ke Bengkulu pada waktu itu adalah para pelaut ulung di bawah pimpinan Imam Maulana Irsyad.

Mereka tiba di Bengkulu pada tahun 1336 Masehi (756/757 Hijriah), setibanya di Bengkulu kaum Syiah penyayang Amir Hussain ini langsung melaksanakan rangkaian Upacara Ritual Tabot yang diselenggarakan selama 10 hari, yakni dari akhir bulan Dzulhijjah $756 \mathrm{H}$ sampai dengan tanggal 10 Muharram $757 \mathrm{H}$. Nama Imam Maulana Irsyad dan kawan-kawan ini kurang dikenal dalam sejarah, hal ini mungkin mereka pada waktu itu tidak menetap secara tetap di Bengkulu. Nama yang lebih dikenal dalam sejarah Tabot di Bengkulu adalah Syekh Burhanuddin (Imam Senggolo). Syekh Burhanuddin hidup di Bengkulu pada masa Inggris sudah masuk ke Bengkulu, yakni antara tahun 1685 sampai dengan 1825 .

Seiring perkembangannya, festival budaya Tabot yang secara rutin digelar selama 10 hari setiap tahunnya, mampu menjadi magnet budaya dan sejarah Provinsi Bengkulu. Digelarnya tradisi ini mampu menyedot animo masyarakat melalui kemeriahan nuansa yang menyertainya. Pada tahun 2017 yang lalu, Tabot juga dilengkapi perlombaan kesenian dan pameran produk unggulan daerah dari 10 kabupaten dan kota. Menariknya, tradisi ini juga sebagai isyarat mudik bagi perantau asal Bengkulu untuk merindukan kampung halamannya.

Nilai sejarah sudah sangat jelas, mengingat Tradisi Tabot ditujukan untuk mengenang kisah kepahlawanan cucu Nabi Muhammad SAW, Husein bin Ali. Sebuah ekspresi ketidaksetujuan terhadap perlakuan Bani Umayyah, terkhusus kepada Yazid bin Muawiyah, termasuk juga Ubaidillah bin Ziyad yang memerintahkan penyerangan terhadap Hussein bin Ali beserta laskar yang menyertainya. Sementara itu, nilai sosial lebih berupa nasehat kepada khalayak bahwa tidak dibenarkan segala bentuk praktik penghalalan segala cara untuk meraih puncak kekuasaan. Selain itu, juga sebagai bentuk keprihatinan sosial. Hanya saja, secara sosial juga tradisi ini tidak terlepas dari ketidakbijaksanaan dalam menyikapi, sehingga seringkali terlepas dari nilai luhur yang terkandung di dalamnya.

\section{2) Pendekatan Etnomatematika dengan RME}

Pada proses pembelajaran, guru dapat memotivasi siswa agar lebih tertarik mempelajari matematika dengan mengaitkan materi yang diajarkan dengan contoh nyata model matematika materi yang diajarkan dalam kehidupan sehari-hari. Sebagian kecil siswa yang belum mengetahui tentang model matematika, walaupun dalam lingkungan budayanya sudah ada, siswa akan merasa tertantang untuk mencari tahu. Secara tidak langsung hal ini akan memberikan motivasi belajar untuk lebih memahami materi sekaligus mengenal lingkungan budayanya.

Rachmawati (2012) menyatakan bahwa strategi yang dapat digunakan guru untuk mengajarkan matematika berbasis etnomatematika adalah dengan menerapkan pembelajaran Contextual Teaching and Learning atau pembelajaran matematika dengan Pendekatan Matematika Realistik. Kedua strategi ini merupakan konsep pembelajaran yang membantu guru mengaitkan antara materi yang diajarkan dengan situasi dunia nyata siswa dan mendorong siswa membuat hubungan antara pengetahuan yang dimilikinya dengan penerapannya dalam 
kehidupan mereka. Sehingga diharapkan hasil pembelajaran lebih bermakna bagi siswa.

Matematika Realistik mendasarkan aktivitas pembelajaran matematika berdasarkan tahap perkembangan siswa, yang dapat dianalogikan dengan fenomena gunung es (iceberg). Ilmu matematika formal yang nampak dari diri siswa merupakan puncak dari gunung es. Meskipun ilmu abstrak tersebut terlihat sangat sedikit, ilmu tersebut dibangun oleh kaki-kaki gunung es yang sangat besar dan banyak tetapi tidak terlihat. Jika pondasi gunung es rapuh maka puncaknya akan mudah roboh. Begitu pula dengan ilmu matematika yang dibangun oleh siswa. Jika dasar-dasar ilmu matematika informal siswa tidak kokoh, maka formalnya juga akan mudah lupa atau hilang sehingga pemahamannya kurang.

Pembelajaran yang berbasis Etnomatematika Bengkulu adalah hasil kebudayaan yang ada di masyarakat Bengkulu, baik berupa artefak maupun kebiasaan adat istiadat Bengkulu. Salah satu contoh pembelajaran berbasis etnomatematika yang ada di Bengkulu adalah konsep Dimensi Tiga pada bentuk rumah adat Bengkulu dan Budaya Tabot.

Selain itu, cara lain memanfaatkan simbol etnomatematika yang terdapat di bangunan Tabot dalam pembelajaran adalah dengan menjadikan pengetahuan tentang simbol etnomatematika yang terdapat di bangunan Tabot tersebut sebagai bahan rujukan dalam penyampaian materi maupun pembuatan soal kontekstual yang sesuai dengan latar belakang budaya siswa. Salah satu contoh tabot Bengkulu dapat dilihat pada gambar berikut:

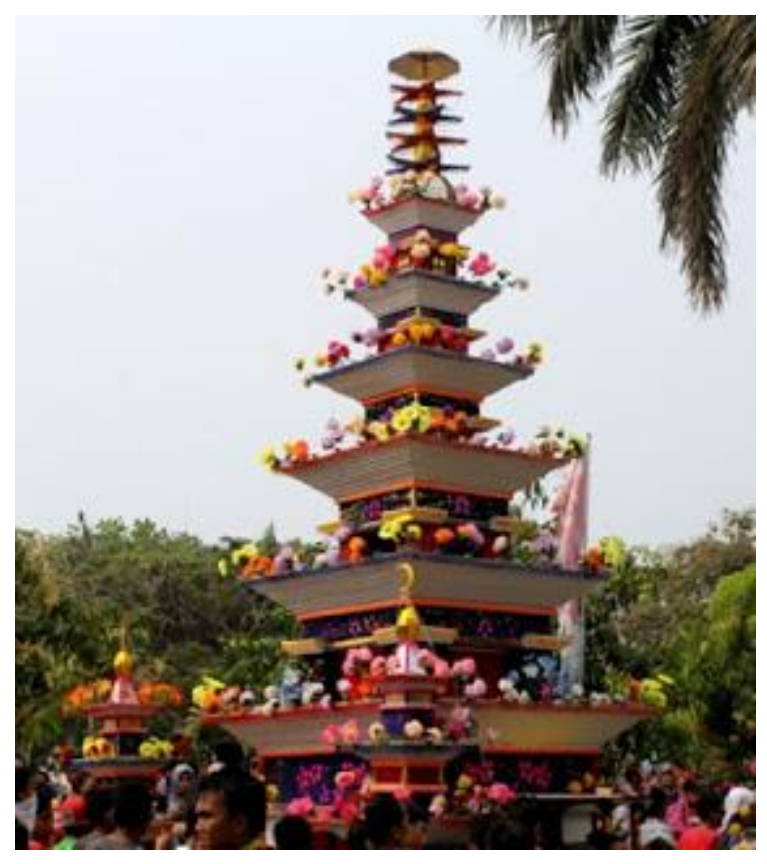

Gambar 1. Bangunan Tabot Bengkulu 1 (Sumber: https//www.google.com)

Pada awal pendekatan pembelajaran dengan pendekatan matematika realistik, siswa melakukan aktivitas berdasarkan permasalahan realistik, selanjutnya memodelkan masalah berdasarkan pemahaman mereka tentang situasi permasalahan realistik yang diberikan. Pada tahap berikutnya siswa diperkenalkan alat peraga 
bangunan tabot sebagai model dari macam-macam bangun ruang geometri yang ada di tabot untuk masalah real yang diberikan pada tahap orientasi masalah. Selanjutnya pada tahap pembuatan pondasi, gambaran siswa tentang permasalahan menggunakan alat peraga membawa mereka menuju gagasan penggunaan bangun ruang sebagai model untuk matematika formal. Pada akhirnya siswa dapat menyelesaikan permasalahan bangun ruang khususnya kubus dan balok dengan menggunakan prosedur formal. Penerapan model realistik dalam pembelajaran matematika berbasis etnomatematika disajikan sebagai berikut:

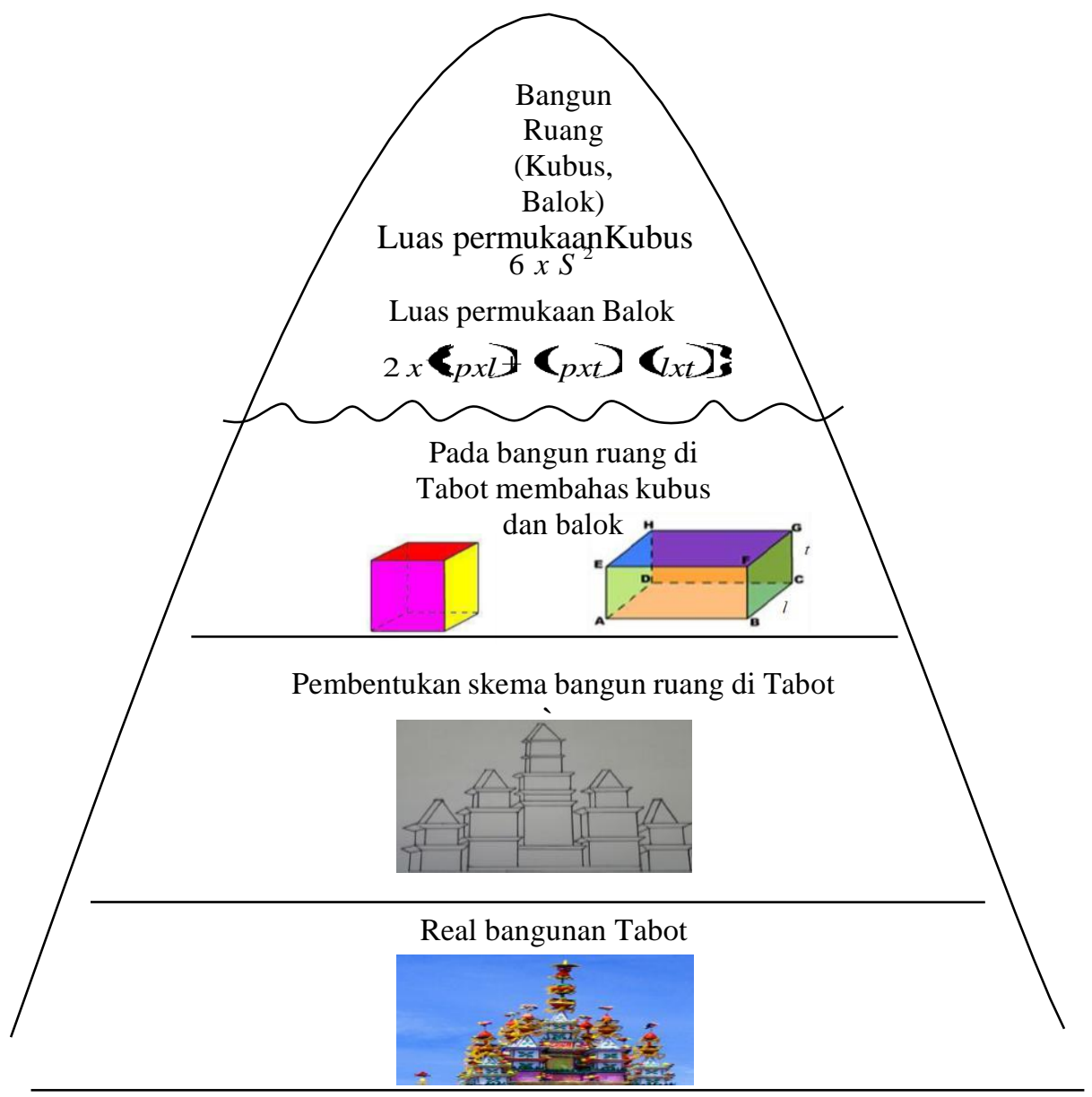

Gambar 2. Iceberg dalam RME 


\section{3) Identifikasi objek Etnomatematika pada bangunan Tabot}

Etnomatematika pada Tabot antara lain dapat dilihat pada bagian-bagian Tabot, sebagai berikut:

Tabel 1. Bagian-bagian Tabot

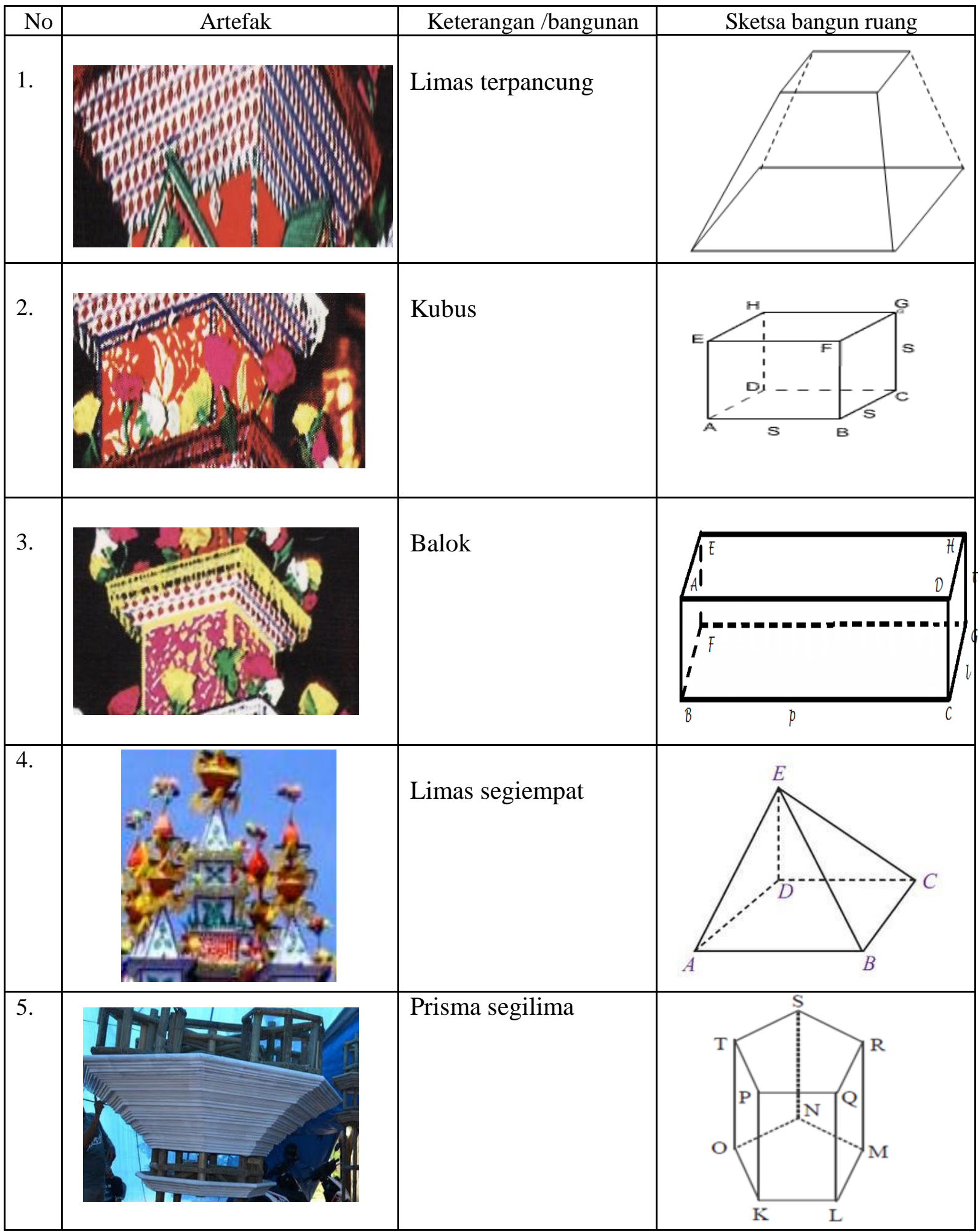

(Sumber: https://www.google.co.id/search?q=tabot+bengkulu) 
Berikut contoh permasalahan yang dibuat berdasarkan konsep pembelajaran realistik berbasis etnomatematika tabot Bengkulu.

\section{Ilustrasi 1}

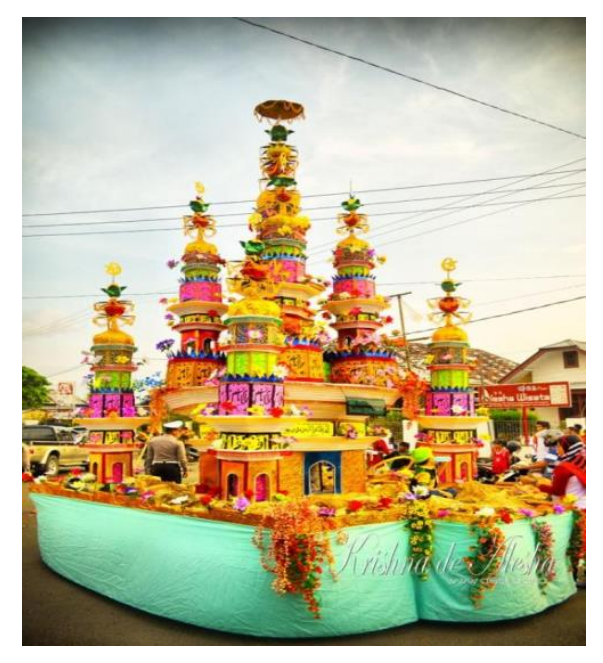

Gambar 3. Bangunan Tabot Bengkulu 2 (Sumber: https//www.google.com)

Ilustrasi masalah!

Pada tahun 2019, Rika dan keluarganya liburan di kota Bengkulu untuk melihat festival Tabot. Kemudian Rika mengamati ada berbagai bentuk bangunan yang terdiri dari geometri bangun ruang pada tabot. Setelah mengamati Rika banyak menemukan bangun ruang, salah satunya yang menarik perhatian Rika adalah bangun ruang kubus dan balok yang pernah dipelajari pada pelajaran matematika minggu lalu. Kemudian Rika ingin mengetahui bagian apa saja yang terdapat di kubus dan balok tersebut, bantulah Rika untuk mempelajari bangun ruang kubus dan balok.

Aktivitas siswa yang dapat dibuat berdasarkan ilustrasi tersebut antara lain:

(1) Dapatkah kalian menggambarkan bangun ruang yang semua sisinya sama, yaitu berbentuk persegi? Kemudian berilah nama di setiap sudutnya!

(2) Titik sudut adalah pertemuan tiga rusuk yang bertemu pada satu titik (titik pojok). Berapakah jumlah titik sudut berdasarkan gambar yang telah kalian buat pada permasalahan (1)? Sebutkan!

(3) Sisi adalah bangun datar, masing-masing sisi perseginya sama besar. Berdasarkan gambar yang telah kalian buat pada permasalahan (1), bantulah Rika menemukan berapa banyaknya sisi yang dimiliki? dan sebutkan!

(4) Diketahui rusuk adalah garis potong antara sisi-sisi. Rusuk tersebut memiliki panjang sama. Tentukanlah banyaknya rusuk yang dimiliki pada gambar yang telah kalian buat pada permasalahan (1)!

(5) Diagonal sisi adalah ruas garis yang terbentuk oleh sudut yang berhadapan pada satu bidang. Setiap sisi terdapat 2 diagonal sisi, berdasarkan gambar yang telah kalian buat pada permasalahan (1), hitunglah banyaknya diagonal sisinya dengan menggambarkan salah satu jaring-jaringnya! 
Berdasarkan permasalahan 1 sampai 5. Bangun ruang apakah yang kalian gambar tersebut? dan bisakah kalian membantu Rika membuat kesimpulan tentang bangun ruang tersebut?

\section{Ilustrasi II}

Nia baru saja pulang dari menonton perayaan festival Tabot Bengkulu, Nia membeli oleh-oleh yang berupa bangunan tabot mini. Minggu lalu Nia pernah belajar matematika materi kubus dan balok sehingga sekarang Nia tertarik ingin mengetahui luas permukaan kubus dan balok tersebut dengan menggunakan karton. Untuk membuat kubus dan balok dengan karton, maka Nia harus mengetahui luas permukaan kubus dan balok pada Tabot mini tersebut. Sekarang bantulah Nia menentukan luas permukaan kubus dan balok!

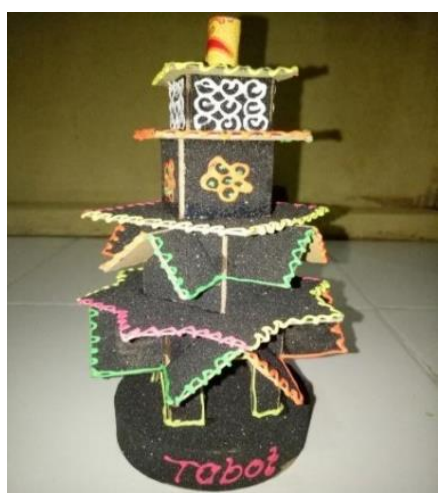

Aktivitas siswa yang dapat dibuat berdasarkan ilustrasi tersebut antara lain:

(1) Buatlah sebuah jaring-jaring kubus, kemudian buka jaring-jaring kubus tersebut. Setelah membuka jaring-jaring kubus, ada berapakah persegi yang dimiliki oleh kubus?

(2) Ingatkah kalian cara mencari luas persegi? diketahui bahwa setiap rusuk persegi memiliki ukuran yang sama, maka untuk menghitung luas setiap persegi kubus tersebut adalah? (Jika rusuknya dilambangkan dengan $\boldsymbol{p}$ ).

(3) Jika luas permukaan kubus sama dengan menghitung luas jaring-jaringnya, maka hitunglah luas seluruh permukaan pada kubus tersebut jika diketahui rusuknya $10 \mathrm{~cm}$. Jawablah berdasarkan pengetahuan yang telah kalian dapatkan pada langkah sebelumnya!

(4) Untuk menentukan luas permukaan balok, perhatikan bahwa!

Balok mempunyai tiga pasang sisi yang tiap pasangnya sama dan sebangun, yaitu:

Sisi ABCD sebangun dengan sisi

Sisi ADHE sebangun dengan sisi

Sisi ABFE sebangun dengan sisi

Maka diperoleh:

(a) Luas permukaan $\mathrm{ABCD}=$ luas permukaan

(b) Luas permukaan ADHE = luas permukaan

(c) Luas permukaan ABFE = luas permukaan

Dengan demikian, luas permukaan balok sama dengan jumlah ketiga pasang sisi yang saling kongruen pada balok tersebut. Bukalah balok sehingga akan memperoleh jaring-jaring balok. 


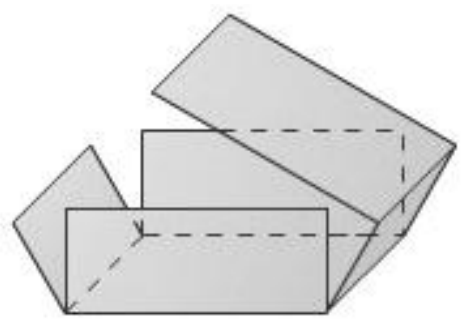

(1) Buatlah salah satu jaring-jaring balok berdasarkan gambar di atas!

(2) Diketahui bahwa pada gambar di bawah ini $p$ adalah panjang (rusuk) balok, $l$ adalah lebar balok, dan $t$ adalah tinggi balok. Tentukan bagaimana cara mencari luas seluruh permukaan dari sisi balok tersebut apabila:

- Sisi atas dan bawah

Jumlah luas $=2 \times(\ldots . \ldots)$

- $\quad$ Sisi depan dan belakang

Jumlah luas $=2 \times(\ldots . . .$.

- Sisi kanan dan kiri

Jumlah luas $=2 \times(\ldots . . .$.

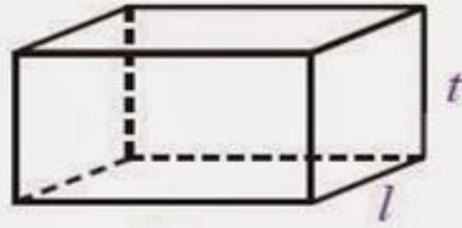

$p$

\section{SIMPULAN DAN SARAN}

Budaya Tabot yang merupakan tradisi tahunan masyarakat Bengkulu memberikan banyak hal selain memiliki nilai spiritual dan nilai sejarah, ternyata juga dapat dimanfaatkan sebagai media pembelajaran matematika terutama pada materi bangun ruang. Bentuk bangunan tabot yang sudah dikenal para siswa di Bengkulu menjadikan pembelajaran bangun ruang dapat lebih mudah dipahami siswa karena telah melekat dengan budaya lokal mereka tersebut.

Banyak budaya lokal Bengkulu lain yang dapat dimanfaatkan untuk media pendekatan pembelajaran matematika seperti kain besurek yang sangat erat kaitannya dengan materi perbandingan dan transformasi objek. Pendekatan etnomatematika pada kain besurek memberikan nuansa lain dalam proses pembelajaran matematika sekolah.

\section{DAFTAR PUSTAKA}

Bishop. 2001. What Values Do You Teach When You Teach Mathematics? Teaching Children Mathematics (Ed.Anne Reynolds dan Jim Dorward). Australian Research Council and Jointly Conducted by Monash University.

Direktorat Sejarah dan Nilai Tradisional Depdikbud. 1992. Upacara Tabut: Upacara Tradisional Daerah Bengkulu di Kotamadya Bengkulu.

https://www.google.co.id/search?q=tabot+bengkulu

Marsigit, Setiana, D.S., Hardiarti, S. 2018. Pengembangan Pembelajaran Matematika Berbasis Etnomatematika. Prosiding Semnar Nasional Etnomatnesia. ISBN 978-602-6258-07-6. [Online]. Tersedia: http://www.jurnal.ustjogja.ac.id/index.php/etnomatnesia/article/viewFile/2291/ 1254. 
Rachmawati, Inda. 2012. Eksplorasi Etnomatematika Masyarakat. Jurnal MATHEdunesa, Vol. 1(1) : 70-77. [Online]. Tersedia: https://jurnalmahasiswa.unesa.ac.id/index.php/mathedunesa/article/view/249/p df

Sirate, F. S. 2012. Implementasi Etnomatematika dalam Pembelajaran Matematika pada Jenjang Pendidikan Sekolah Dasar. Lentera Pendidikan, Vol. 15(1) : 41-54.

Sugiman. 2008. Pandangan Matematika Sebagai Aktivitas Insani Beserta Dampak Pembelajarannya. Jurnal Pendidikan Matematika, Vol 2(2) : 61-71.

Tandililing, Edy. 2013. Pengembangan Pembelajaran Matematika Sekolah dengan Pendekatan Etnomatematika Berbasis Budaya Lokal Sebagai Upaya Untuk Meningkatkan Kualitas Pembelajaran Matematika di Sekolah. Makalah Pada Prosising Seminar Nasional Matematika dan Pendidikan Matematika. Jurusan Pendidikan Matematika FMIPA UNY, Yogyakarta, 9 November 2013. Hal: 193-202. ISBN : 978- 979-16353-9-4.

Wahyuni, Astri 2013. Peran Etnomatematika dalam Membangun Karakter Bangsa. Makalah Pada Prosising Seminar Nasional Matematika dan Pendidikan Matematika. Jurusan Pendidikan Matematika FMIPA UNY, Yogyakarta, 9 November 2013. Hal: 113-118. ISBN : 978- 979-16353-9-4.

Widada, W., Herawaty, D., and Lubis, A. N. M. T. 2018. Realistic Mathematics Learning Based on The Ethnomathematics in Bengkulu to Improve Students' Cognitive Level. Journal of Physics: Conference Series, 1088. https://doi.org/10.1088/1742-6596/1088/1/012028 